\title{
Enzymatic Characterization of Fructose 1,6-Bisphosphatase II from Francisella tularensis, an Essential Enzyme for Pathogenesis
}

\author{
Hiten J. Gutka ${ }^{1,2,3} \cdot$ Nina M. Wolf ${ }^{1}$ • \\ Jasper Marc G. Bondoc ${ }^{1}$. Farahnaz Movahedzadeh ${ }^{1,2}$
}

Received: 15 February 2017 / Accepted: 11 May 2017 /

Published online: 25 May 2017

C) The Author(s) 2017. This article is an open access publication

\begin{abstract}
The $g l p X$ gene from Francisella tularensis encodes for the class II fructose 1,6bisphosphatase (FBPaseII) enzyme. The $g l p X$ gene has been verified to be essential in $F$. tularensis, and the inactivation of this gene leads to impaired bacterial growth on gluconeogenic substrates. In the present work, we have complemented a $\Delta g l p X$ mutant of Escherichia coli with the $g l p X$ gene of $F$. tularensis (FTF1631c). Our complementation work independently verifies that the $g l p X$ gene (FTF1631c) in F. tularensis is indeed an FBPase and supports the growth of the $\Delta g l p X E$. coli mutant on glycerol-containing media. We have performed heterologous expression and purification of the $g l p X$ encoded FBPaseII in F. tularensis. We have confirmed the function of $g l p X$ as an FBPase and optimized the conditions for enzymatic activity. $\mathrm{Mn}^{2+}$ was found to be an absolute requirement for activity, with no other metal substitutions rendering the enzyme active. The kinetic parameters for this enzyme were found as follows: $\mathrm{K}_{\mathrm{m}} 11 \mu \mathrm{M}, \mathrm{V}_{\max } 2.0 \mathrm{units} / \mathrm{mg}, \mathrm{k}_{\mathrm{cat}} 1.2 \mathrm{~s}^{-1}, \mathrm{k}_{\mathrm{cat}} / \mathrm{K}_{\mathrm{m}}$ $120 \mathrm{mM}^{-1} \mathrm{~s}^{-1}$, and a specific activity of 2.0 units $/ \mathrm{mg}$. Size exclusion data suggested an abundance of a tetrameric species in solution. Our findings on the enzyme's properties will facilitate the initial stages of a structure-based drug design program targeting this essential gene of $F$. tularensis.
\end{abstract}

Keywords Gluconeogenesis $\cdot$ Francisella tularensis $\cdot$ Fructose-1,6-bisphosphatase $\cdot$ Enzymatic activity $\cdot g l p X$

Farahnaz Movahedzadeh

movahed@uic.edu

1 Institute for Tuberculosis Research, College of Pharmacy, University of Illinois at Chicago, Chicago, IL, USA

2 Department of Medicinal Chemistry and Pharmacognosy, College of Pharmacy, University of Illinois at Chicago, Chicago, IL, USA

3 Present address: Oncobiologics Inc., Cranbury, NJ, USA 


$\begin{array}{ll}\text { Abbreviations } & \\ \text { F16BP } & \text { Fructose-1,6-bisphosphate } \\ f b p & \text { Class I Fructose-1,6-bisphosphatase gene } \\ \text { FBPaseII } & \text { Class II Fructose-1,6-bisphosphatase protein } \\ F t & \text { Francisella tularensis } \\ F t \text { FBPaseII } & \text { Fructose-1,6-bisphosphatase from Francisella tularensis } \\ g l p X & \text { Class II Fructose-1,6-bisphosphatase gene } \\ \text { IPTG } & \text { Isopropyl } \beta \text {-D-1-thioglactopyranoside } \\ \text { JB108 } & \text { E. coli BL21(DE3) strain lacking } f b p \text { gene } \\ \text { JB108::pET15b } & \text { JB108 transformed with empty plasmid } \\ \text { JB108::pET15b-FtglpX } X & \text { JB108 transformed with plasmid containing glpX gene } \\ \text { JLD2402 } & \text { E. coli strain lacking } f b p \text { gene and glpX gene } \\ \text { JLD2404 } & \text { E. coli strain lacking } f b p \text { gene } \\ \text { SEC } & \text { Size exclusion chromatography } \\ \text { Tricine } & \text { N-(2-Hydroxy-1,1-bis(hydroxymethyl)ethyl)glycine } \\ \text { Tris } & \text { Tris(hydroxymethyl)aminomethane } \\ \text { HEPES } & \text { 2-[4-(2-hydroxyethyl)piperazin-1-yl]ethanesulfonic acid } \\ \text { MOPS } & \text { 3-Morpholinopropane-1-sulfonic acid } \\ \text { Bis-tris } & \text { 2-[Bis(2-hydroxyethyl)amino]-2-(hydroxymethyl)propane-1,3-diol }\end{array}$

\section{Introduction}

Francisella tularensis (F. tularensis) is the etiologic agent of tularemia. This highly virulent bacterium is considered high risk for use as a biological weapon since the minimal infectious dose for human is only 10 bacteria [1]. Identifying new drugs and antibiotics against such pathogens is vital. Therefore, the execution of a rational structure-based drug design study targeting key regulatory proteins and enzymes in F. tularensis would ultimately lead to a novel antibiotic which could potentially become a drug.

The virulence of several $F$. tularensis SCHU S4 strain mutants was assessed by following the outcome of infection after intradermal infection. In this study, the virulence of 20 in-frame deletion mutants and 37 transposon mutants were assessed [2]. The majority of the mutants did not show an increase in prolonged time to death. However, mutations in six unique targets resulted in significantly prolonged time to death and mutations in nine targets, including $\operatorname{glp} X$, and led to marked attenuation with an $\mathrm{LD}_{50}$ of $>10^{3} \mathrm{CFU}$. Compared to the wild-type strain with the $\mathrm{LD}_{50}$ of one CFU, glpX mutant showed a marked attenuation with an $\mathrm{LD}_{50}$ of $10^{7} \mathrm{CFU}$ or greater [2]. The extreme attenuation of the $\Delta g \operatorname{lp} X$ mutant suggests that $g \operatorname{lp} X$ is required for the virulence of $F$. tularensis in vivo [2].

More recently, the $g \operatorname{lp} X$ of $F$. tularensis was demonstrated to be an essential component for bacterial growth and a requirement for mouse infection [3]. Growth of wild-type and the $\Delta g l p X$ mutant of $F$. tularensis were unaffected by glucose and ribose, while the $\Delta g l p X$ mutant greatly impaired growth on glycerol, pyruvate, and an amino acid cocktail. A challenge of wild-type and $\Delta g l p X$ mutant $F$. tularensis, subspecies $F$. novicida, in mice resulted in an $80 \%$ survival rate for mice infected with the $\Delta g l p X$ mutant after 10 days, while mice who received the wildtype bacteria all died after 3 days [3].

Our work on the $g l p X$ encoded FBPase II in Mycobacterium tuberculosis indicates that it is essential for the long-term survival and proliferation in mice model [4]. We were able to 
successfully demonstrate that the $g l p X$ encoded FBPase is an FBPase II [5]. Further, we reported the expression, purification and biochemical characterization of this enzyme in M. tuberculosis $[6,7]$. The sequence similarity of the $g l p X$-encoded proteins in both $M$. tuberculosis and F. tularensis promoted us to investigate the properties of this protein in F. tularensis as well.

There are five known classes of FBPases [8-10]. Most organisms contain a mixture of Class I and II. Class I FBPases, the most common form, are found in several eukaryotes and some prokaryotes while Class II is mainly found in bacteria with a few cases in eukaryotes [11]. Class III was defined for a unique FPBase from Bacillus substilus, structurally unrelated to the other classes [11]. Class IV from archaea have both inositol monophosphatase and fructose-1,6-bisphosphatase activity [12]. Class V FBPases are found in thermophile prokaryotes and contain an unusual 4-layer $\alpha-\beta-\beta-\alpha$ fold instead of the common 5-layer $\alpha-\beta-\alpha-\beta-\alpha$ fold [13]. Escherichia coli has both Class I $(f b p)$ and Class II $(g l p X)$. To date, F. tularensis contains one proposed FBPase Class II, $g l p X$. The $g l p X$ gene is required for the virulence of F. tularensis in vivo [2,3]. There is no known Class I fructose 1,6-bisphosphatase (FBPase) in F. tularensis, and it is expected that the $g l p X$ gene product is responsible for the catalysis of fructose 1,6-bisphosphate (F16BP) due to sequence similarity. However, the exact biochemical activity, or function of the $g l p X$ gene product, fructose 1,6-bisphosphatase (FBPaseII), has not been experimentally verified. Here, we have biochemically characterized the FBPaseII of F. tularensis (FtFBPaseII) to verify functionality, specificity and stability. We also describe preliminary structural characterization by size exclusion chromatography of FtFBPaseII. These experiments serve as a foundation for a structure-based drug design strategy targeting the FtFBPaseII enzyme.

\section{Materials and Methods}

All materials were purchased from Thermo Fisher Scientific, Waltham, MA, unless noted. Enzymes for the secondary assay and substrate compounds were purchased from Sigma Aldrich, St. Louis, MO.

\section{Cloning}

The F. tularensis glpX gene was codon optimized, synthesized, and cloned into a pET15b vector suitable for genetic complementation studies and recombinant expression (CelTek Bioscience, Franklin, TN). The construct was sequenced for its accuracy, subjected to restriction digestion with BamHI/XbaI, and the insertion of the FtglpX gene was confirmed.

\section{Complementation}

The pET15b-Ftglp $X$ construct was transformed into E. coli strain JLD2402 (TL524 glpX::Spc ${ }^{\mathrm{r}}$ $\Delta f b p 287$ zjg920::Tn10), which lacks both $f b p$ and $g l p X$, (JLD2402-pET15b-FtglpX), and JLD2404 (TL524 $g l p X^{+} \Delta f b p 287$ zjg920::Tn10), which lacks only fbp (JLD2404-pET15bFtglpX) [14]. Antibiotic-resistant transformants were grown on minimal media plates containing glucose or glycerol as the sole carbon source and isopropyl $\beta$-D-1-thioglactopyranoside (IPTG) to induce expression of the $g \operatorname{lp} X$ gene. Additionally, the pET15b-FtglpX construct was transformed into E. coli strain JB108 (BL21(DE3) zjg920::Tn10 $\Delta f b p 287$ ) (JB108::pET15b- 
FtglpX) [14], which was grown in minimal medium containing glycerol. Appropriate control strains of E. coli BL21(DE3) (Novagen, Billerica, MA), untransformed JB108, and JB108 strain transformed with pET15b (JB108::pET15b) were also run with appropriate concentrations of IPTG. The plates were incubated at $27^{\circ} \mathrm{C}$ for $36 \mathrm{~h}$ to visually confirm bacterial growth.

\section{Species Primary Sequence Comparison}

The $g l p X$ sequence of $F$. tularensis was obtained from the KEGG database (FTF1631c), the E. coli sequence was obtained from SWISSPROT (accession no. P28860), the C. glutamicum sequence was obtained from GenBank (accession no. 19552240), the M. tuberculosis sequence was obtained from the Tuberculist server (http:/genolist.pasteur.fr/TubercuList/; gene name Rv1099c), and the M. smegmatis sequence was derived from genomic sequences obtained from the Institute for Genomic Research website (http://www.tigr.org/). The exact start residue of the proteins is known only for C. glutamicum [15].

\section{Expression and Purification}

The pET-15b-FtglpX construct expressing N-terminal histidine-tagged FtFBPaseII was transformed into $E$. coli strain BL21(DE3). The positive colonies were grown on LB agar containing ampicillin $(100 \mu \mathrm{g} / \mathrm{mL})$. Then, the transformants were grown overnight in LB broth (with ampicillin at $100 \mu \mathrm{g} / \mathrm{mL}$ ) at $37^{\circ} \mathrm{C}$ in an incubator shaking at $180 \mathrm{rpm}$. After $16 \mathrm{~h}, 1.0 \mathrm{~mL}$ of this culture was transferred to $100 \mathrm{~mL}$ of LB broth (with ampicillin at $100 \mu \mathrm{g} / \mathrm{mL}$ ) and incubated at $37{ }^{\circ} \mathrm{C}$. When the $\mathrm{OD}_{600}$ reached 0.6 , the culture was induced with IPTG $(1 \mathrm{mM})$. After $5 \mathrm{~h}$, the cell pellet was harvested and frozen at -20 or $-80{ }^{\circ} \mathrm{C}$ until further use.

Purification of the FtFBPaseII was performed in a similar manner as described for $M t$ FBPaseII [6], except that the final buffer exchange and concentration of the purified protein was performed using an Amicon-15 Ultracel $30 \mathrm{~K}$ centrifuge concentrator or Zeba spin desalting column. Protein molecular mass was determined using electron spray ionization mass spectrometry coupled with HPLC (Thermo Orbitrap Velos Pro MS, Agilent 1200 nano HPLC) through the Research Resources Center at UIC.

\section{Size Exclusion Chromatography}

Size exclusion chromatography (SEC) was performed on an ÄKTA purifier FPLC system in a similar manner to that described for $M t$ FBPase [6]. Retention times were determined by monitoring the absorbance at $280 \mathrm{~nm}$. FtFBPaseII was injected at a concentration of $1.0 \mathrm{mg} / \mathrm{mL}$. Total protein quantification was performed using the Pierce 660-nm kit. Bovine serum albumin (BSA) was used as the standard [ThermoFisher Scientific]. The relative elution $\left(K_{a v}\right)$ and hence the molecular weight for $F$. tularensis FBPaseII was estimated as described for $M t$ FBPaseII using thyroglobulin (bovine) $670 \mathrm{kDa}$, gamma globulin (bovine) $158 \mathrm{kDa}$, ovalbumin (chicken) $44 \mathrm{kDa}$, myoglobulin (horse) $17 \mathrm{kDa}$, and vitamin B12 $1350 \mathrm{Da}$. Since raw data was no longer available, previously acquired images were uploaded to http://arohatgi.info/WebPlotDigitizer and the data was processed with the $\Delta \mathrm{x}$ step interpolation algorithm of 0.01 units and $0 \%$ smoothing to create Fig. 4a, b (WebPlotDigitizer, Austin, TX). 


\section{Enzymatic Activity}

Assays were conducted in $50 \mathrm{mM}$ Tris $\mathrm{pH} 8.0$ with $100 \mathrm{mM} \mathrm{Mn}^{2+}, 50 \mathrm{nM}$ FtFBPaseII, and $100 \mu \mathrm{M}$ F16BP unless otherwise indicated. Protein concentration was determined by absorbance at $280 \mathrm{~nm}$ with extinction coefficient $12,950 \mathrm{M}^{-1} \mathrm{~cm}^{-1}$. Assays were performed at room temperature, approximately $22-24{ }^{\circ} \mathrm{C}$.

A malachite green assay [16] was used to test for metal requirements, buffer system, and substrate specificity. Enzymatic solutions were allowed to react for $15 \mathrm{~min}$ before being quenched with the malachite green agent. The absorbance at $630 \mathrm{nM}$ was measured after an additional $5 \mathrm{~min}$ for dye development. The following metals, as chloride salts at $100 \mathrm{mM}$, were tested for absolute requirement for activity: $\mathrm{Mg}^{2+}, \mathrm{Ca}^{2+}, \mathrm{Zn}^{2+}, \mathrm{Fe}^{2+}, \mathrm{Cu}^{2+}, \mathrm{Co}^{2+}, \mathrm{Ni}^{2+}, \mathrm{K}^{+}$, $\mathrm{Na}^{+}$, and $\mathrm{Mn}^{2+}$. Different buffering systems were tested at $\mathrm{pH} 7.5$ and $50 \mathrm{mM}$ buffer component. The $\mathrm{pH}$ of $50 \mathrm{mM}$ Tris was screened (7.0-9.0 $\mathrm{pH}$ units). The amount of phosphate released was determined by using a calibration curve of potassium phosphate standard in the presence of $50 \mathrm{mM} \mathrm{Mn^{2+ }}$. Different substrates at $1 \mathrm{mM}$ (D-fructose-1,6-bisphosphate, Snglycerol-6-phosphate, 3-phosphoglycerate, D-mannose-6-phosphate, D-fructose-6-phosphate, D-glucose-6-phosphate, D-fructose-1-phosphate, D-ribulose-1,5-bisphosphate, D-glucose-1,6bisphosphate) were tested for substrate specificity against FtFBPaseII and adjusted for autophosphohydrolysis.

A coupled assay [6, 15], measuring production of NADPH at $340 \mathrm{~nm}$, was used to determine enzymatic parameters and analyzed with a non-linear fit of Michaelis-Menten and $\mathrm{k}_{\text {cat }}$ equations (fixing $\mathrm{E}_{\mathrm{t}}$ at $50 \mathrm{nM}$ ) using GraphPad Prism version 7.0b for Mac (GraphPad Software, La Jolla, CA). Using the coupled assay, the following optimal conditions were found where $F t$ FBPaseII is the limiting reagent: 5 units $/ \mathrm{mL}$ of phosphoglucoisomerase, 2 units $/ \mathrm{mL}$ of glucose-6-phosphate dehydrogenase, $0.3 \mathrm{mM} \mathrm{NADP}^{+}, 15 \mu \mathrm{M}$ F16BP, and $50 \mathrm{nM}$ FBPaseII. $\mathrm{Li}^{+}$sensitivity was assessed with concentrations up to $100 \mathrm{mM}$. The reaction was monitored for $3.5 \mathrm{~min}$. Enzyme inhibition by adenosine diphosphate $(0.6-4 \mathrm{mM})$ and free phosphate $(0.2-10 \mathrm{mM})$ was calculated relative to the unaccompanied enzyme. The residual activity after heating was assessed by incubating protein samples for $30 \mathrm{~min}$ at various temperatures in a water bath $\left(10-80^{\circ} \mathrm{C}\right)$, returning to ice for $15 \mathrm{~min}$ and assaying against a sample on ice for the same length of time.

\section{Results}

\section{F. tularensis glpX Encodes a Class II FBPase which Functionally Complements an $E$. coli $\Delta g l p X / \Delta f b p$ Strain}

In case of $E$. coli, it has been proven that the $g l p X$-encoded FBPase II is not crucial for cell growth and proliferation since a strain lacking the $g l p X$ gene (JLD2403 (fbp1 glpX::Spcr)), successfully grows on LB or glucose, fructose, succinate, or glycerol minimal medium, in both aerobic and anaerobic conditions when the $f b p$-encoded FBPase I (major FBPase in E. coli) is present.

E. coli strains lacking the FBPase I grow normally on glucose but are unable to grow on minimal medium supplemented with glycerol or other gluconeogenic substrates, indicating that chromosomal $g l p X$ even if present does not fully compensate the loss of $f b p$ expression. 
The pET15b-Ftglp $X$ construct was introduced into E. coli strains JLD2402 (TL524 glpX::Spcr $\Delta$ fbp287 zjg-920::Tn10) and JLD2404 (TL524 glpX1 $\Delta$ fbp287 zjg-920::Tn10), the ampicillin resistant colonies were streaked on minimal media plates containing either glucose or glycerol as the sole carbon source, and IPTG was used to induce the expression of the $g l p X$ gene. While the control strains (untransformed JLD2402 and JLD2404) only grew on glucose as a sole carbon source, the pET15b-FtglpX construct transformed into JLD2402 and JLD2404 grew on either glucose or glycerol as the sole carbon source (Fig. 1a). This genetic complementation is indicative of FBPase activity of the $F$. tularensis glpX gene product. However, it is noteworthy that such complementation occurs at $27^{\circ} \mathrm{C}$ over the incubation period of $36 \mathrm{~h}$ (as opposed to the normal growth condition of $37^{\circ} \mathrm{C}$ overnight) which does not rule out the possibility of non-specific complementation. It is important to note that both the strains JLD2402 and JLD2404 lack an overexpressing T7 polymerase gene, yet the pET15b-FtglpX vector could successfully complement both strains. This indicates a possibility of read-through from other promoters.

Since this complementation result is not confirmatory and rather non-specific, we investigated the possibility of pET15b-FtglpX vector complementing the JB108 strain of E. coli. The JB108 strain lacks the functional FBPase I (BL21(DE3) zjg920::Tn10 $\Delta$ fbp287). JB108 is derived from the strain BL21(DE3) which has a host $\mathrm{T} 7$ polymerase gene that permits overexpression of a protein encoded in a pET vector [17]. F. tularensis FBPaseII protein expression from the T7 promoter complements growth of JB108 $\Delta f b p$ E. coli strain on glycerol minimal media in an IPTG concentration-dependent manner (Fig. 1b). Strains JB108, JB108::pET15b, and JB108::pET15b-FtglpX, in which FtFBPaseII is overexpressed from the $\mathrm{T} 7$ promoter, and control strain BL21(DE3) $\left(f b p^{+} g l p X^{+}\right)$were grown in minimal glycerol-containing media. Variable concentrations of IPTG (0 to $1000 \mu \mathrm{M})$ were used. In addition, the growth of JB108::pET15b-FtglpX and the corresponding FBPase activity was directly proportional to the effective IPTG concentration used for growth (Table 1). The coupled spectrophotometric assay was used to measure the FBPase activity in cell-free extracts. As expected, the E. coli JB108 host and JB108::pET15b had very low FBPase expression levels, while the mutant complemented with pET15b-FtglpX showed elevated levels of FBPase activity in an IPTG concentration-dependent manner. This IPTG concentration-dependent expression of the FBPase indicates that $\mathrm{pET} 15 \mathrm{~b}-\mathrm{Ftglp} X$ successfully complements the $E$ coli strain JB108.

Primary sequence comparison of FtFBPaseII, with other known class II FBPases (41-47\% sequence identity), suggests that several regions are conserved. Furthermore, all the important catalytic residues are conserved (Fig. 2). Characteristic conserved regions have been indicated. Also, conserved residues adjacent to the catalytically important residues have been indicated.

\section{Purification}

Significant expression of FtFBPaseII was observed upon induction with $1 \mathrm{mM}$ IPTG in the E. coli cell cultures transformed with the pET15b-FtglpX construct (not shown). The $F t$ FBPaseII, which was overexpressed in $E$. coli, was present in the soluble fraction and the insoluble fraction (Fig. 3, lane 7). The Ni-NTA elute showed no impurities in the gel (Fig. 3, lane 1).

The protein was further purified with SEC. Fractions from the major peak at $200 \mathrm{~mL}$ appeared to have high purity as identified by SDS-PAGE (Fig. 4a) and, hence, were pooled. Since no protein was detected in the small peak at $350 \mathrm{~mL}$ by SDS-PAGE, it is assumed to 

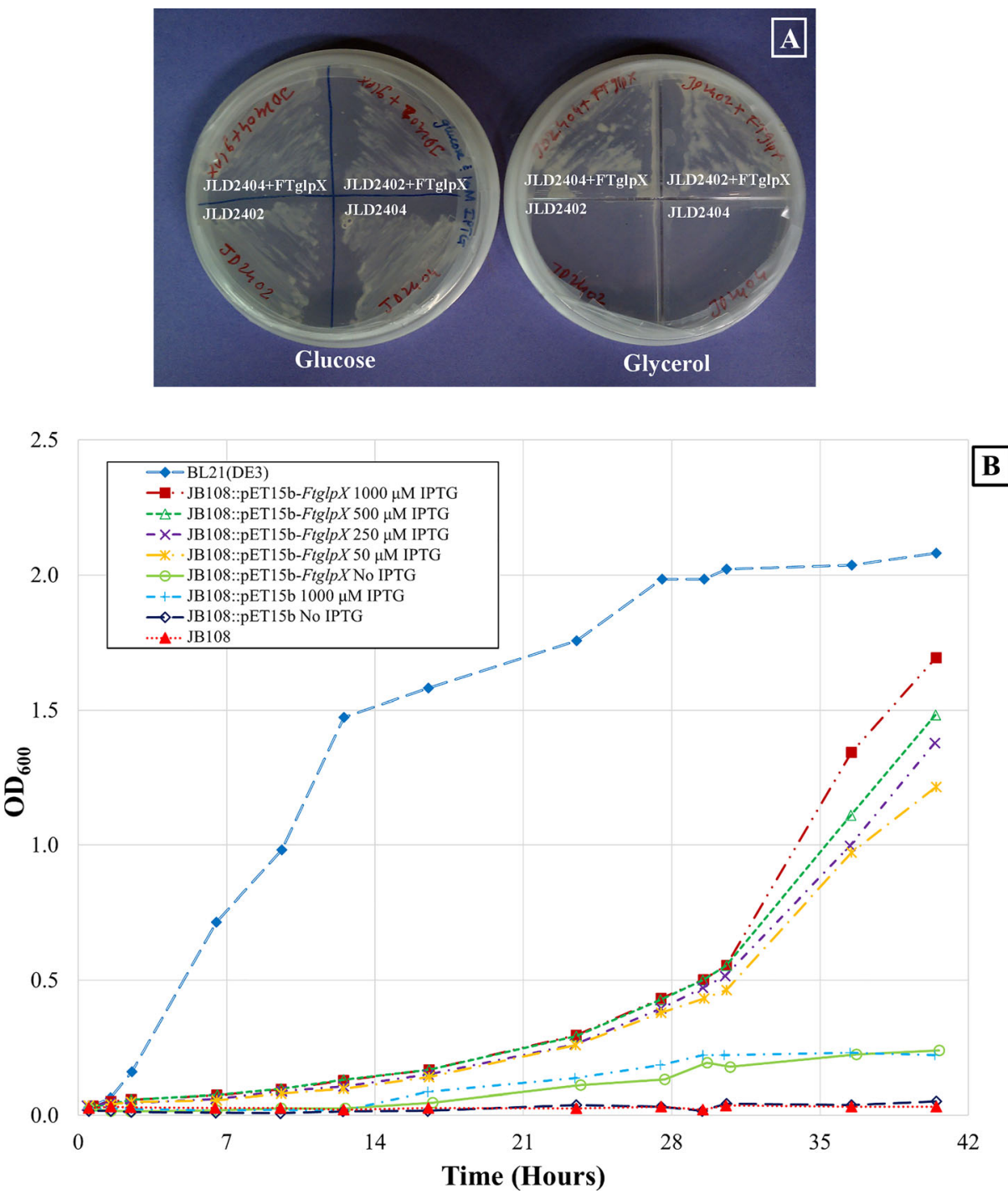

Fig. 1 Growth pattern of the glucose-dependent E. coli strains transformed with FtglpX. JLD2402 and JLD2404 E. coli strains transformed with the $\mathrm{pET} 15 \mathrm{~b}-\mathrm{Ftg} \operatorname{lp} X$ construct were streaked onto minimal agar containing glucose (left) or glycerol (right) as the carbon source (a). The transformed strains grew on minimal agar with glycerol but not the control (untransformed) strains. E. coli strains JB108, JB108::pET15b, JB108::pET15bFtglpX in which $F t$ FBPaseII is expressed from the T7 promoter and BL21(DE3) $\left(f b p^{+} g l p X^{+}\right)$control strain were grown in minimal medium containing glycerol. The growth of JB108::pET15b-FtglpX increased in an IPTG concentration $(0$ to $1000 \mu \mathrm{M})$-dependent manner (b). The starter culture was grown overnight in minimal medium containing glucose. The IPTG levels utilized for strain JB108::pET15b-FtglpX during growth were 0 , $50,250,500$, and $1000 \mu \mathrm{M}$. No IPTG was used for each of BL21(DE3) $\left(f b p^{+} g l p X^{+}\right)$, JB108, JB108::pET15b, and JB108::pET15b-FtglpX strains, which served as controls. This experiment was repeated twice. Samples for measuring FBPase activity were withdrawn at $24 \mathrm{~h}$ post-IPTG induction; the cultures were also supplemented with ampicillin $(100 \mu \mathrm{g} / \mathrm{mL})$

contain dilute protein, non-protein impurities with $\mathrm{A}_{280}$ absorption, or other buffer ingredients. Protein concentration was determined by two methods. Comparison of the Pierce 660-nm kit 
Table 1 FBPase activity in E. coli strains expressing FtFBPaseII protein

\begin{tabular}{lllr}
\hline Strain/construct & {$[$ IPTG] $(\mathrm{mM})$} & $\mathrm{n}$ & FBPase specific activity $\left(\mathrm{nmol} \mathrm{min}^{-1} \mathrm{mg}^{-1}\right)$ \\
\hline BL21(DE3) & 0 & 3 & $16.30 \pm 1.22$ \\
JB108 & 0 & 3 & $0.33 \pm 0.08$ \\
JB108::pET15b & 0 & 3 & $0.09 \pm 0.03$ \\
JB108::pET15b & 1000 & 3 & $0.16 \pm 0.07$ \\
JB108::pET15b-FtglpX & 0 & 6 & $0.33 \pm 0.09$ \\
JB108::pET15b-FtglpX & 50 & 6 & $5.53 \pm 1.13$ \\
JB108::pET15b-FtglpX & 250 & 6 & $9.89 \pm 1.75$ \\
JB108::pET15b-FtglpX & 500 & 6 & $16.72 \pm 1.25$ \\
JB108::pET15b-FtglpX & 1000 & 6 & $21.46 \pm 1.87$ \\
\hline
\end{tabular}

and A280 with predicted extinction coefficient for protein quantification resulted in a ratio of the two predicted values to be $1.06 \pm 0.10(n=3)$, confirming minimal variation between the two techniques.

\section{Molecular Weight Determination and Hydrodynamic Size}

Mass spectrometry experiments indicated a mass of $36,846.6 \mathrm{~g} / \mathrm{mol}$, corresponding to the predicted size of $36,846 \mathrm{~g} / \mathrm{mol}$ with the initial methionine cleaved in situ [18]. The oligomeric state of the FtFBPaseII in solution state was evaluated by SEC. The void volume of the column, as determined by dextran blue, is $V_{o}=39.80 \mathrm{~mL}$; total column volume, $V_{t}$ (also referred to as geometric column volume) $=120 \mathrm{~mL}$ [6]. Using this method, two protein peaks corresponding to molecular weights of 63.8 and $124.9 \mathrm{kDa}$ were observed (Fig. 4b). This observation suggests that at a concentration of $1 \mathrm{mg} / \mathrm{mL}, F$. tularensis FBPaseII exists as a mixture of both dimers and tetramers, assuming the monomer subunit is about $35 \mathrm{kDa}$.

\section{Enzyme Activity}

The activity of FtFBPaseII was tested under various conditions using the malachite green assay. The bivalent metal, $\mathrm{Mn}^{2+}$, was found to be an absolute requirement for activity, with maximum activity at $50 \mathrm{mM} \mathrm{Mn}^{2+}$ (Fig. 5). None of the other bivalent or monovalent metals tested with FtFBPaseII resulted in an active enzyme (Fig. 6). Activity of FtFBPaseII was greatly reduced in tricine; slightly reduced in bis-tris; and showed similar levels of activity in tris, HEPES, and MOPS buffering systems. A buffer $\mathrm{pH}$ of 8.0-8.5 was optimal (Fig. 7). After a 10-min reaction of $\mathrm{FtFBPaseII}$ with F16BP, $26 \mu \mathrm{M}$ phosphate was released, which is a $26 \%$ turnover of substrate. As substrates, sn-glycerol-6-phosphate, 3-phosphoglycerate, D-mannose6-phosphate, D-fructose-6-phosphate, and D-glucose-6-phosphate had less than $2 \%$ activity with $F t$ FBPaseII as compared to F16BP and hence are not substrates for the enzyme (Fig. 8). D-fructose-1-phosphate, D-ribulose-1,5-bisphosphate, and D-glucose-1,6-bisphosphate showed varying phosphate liberation by $F t$ FBPaseII with 8,13 , and $32 \%$ activity, respectively, when compared to activity with F16BP. The residual enzyme activity after heating experiments indicate highest activity with protein incubated at $0-20{ }^{\circ} \mathrm{C}$; at $30{ }^{\circ} \mathrm{C}$ and above, the activity was reduced (Fig. 9).

Using a coupled assay with real-time measurements, $\mathrm{K}_{\mathrm{m}}$ was found to be $11 \mu \mathrm{M}, \mathrm{V}_{\max }$ was 2.0 units $/ \mathrm{mg}$, $\mathrm{k}_{\text {cat }}$ was $1.2 \mathrm{~s}^{-1}, \mathrm{k}_{\text {cat }} / \mathrm{K}_{\mathrm{m}}$ was $120 \mathrm{mM}^{-1} \mathrm{~s}^{-1}$, and specific activity of the enzyme was 2.0 units $/ \mathrm{mg}$. The $\mathrm{R}^{2}$ coefficient of determination was greater than 0.99 . The reaction was 
F.tularensis

M. tuberculosis

E.coli

C.glutamicum

S.PCC6803

T.elongatus

R.salinarium

F.tularensis

M. tuberculosis

E.coli

C.glutamicum

S.PCC6803

T.elongatus

R.salinarium

F.tularensis

M. tuberculosis

E.coli

C.glutamicum

S.PCC6803

T.elongatus

R.salinarium

F.tularensis

M. tuberculosis

E.coli

C.glutamicum

S.PCC6803

T.elongatus

R.salinarium

F.tularensis

M. tuberculosis

E.coli

C.glutamicum

S.PCC6803

T.elongatus

R.salinarium

F.tularensis

M. tuberculosis

E. coli

C.glutamicum

S.PCC6803

T.elongatus

R.salinarium

F.tularensis

M. tuberculosis

E. coli

C.glutamicum

S.PCC6803

T.elongatus

$R$ salinarium
- - - - MNRKVALEAVRVTELAALASWSQMGRGDKIAADQAAVDAMRKALNEVDIDGT - - MELVRVTEAGAMAAGRWVGRGDKEGGDGAAVDAMRELVNSVSMRGV - - - MRRELAIEFSRVTESAALAGYKWLGRGDKNTADGAAVNAMRIMLNQVNIDGT MNLKNPETPDRNLAMELVRVTEAAALASGRWVGRGMKNEGDGAAVDAMRQLINSVTMKGV - - - MDSTLGLEI IEVVEQAAIASAKWMGKGEKNTADQVAVEAMRERMNKIHMRGR - - - MDNVIGLEI IEVVEQAAIASARWMGKGDKNMADQAAVDAMRNRMNQIHMRGR - - MANATLDRNLALEAVRVTELTALSASRLMGRGDEKAADQAAVNAMREALNGLAISGR :* $^{*}$ * $^{*}{ }^{*}::$ : $\quad$ :* $^{*}:$.* $^{* * *}$ :** $^{*} \quad$ * $^{*}:$ : $^{*}$

VVIGEGELDEAPMLYIGEKVGAG-GC - - - - - EVDIALDPLEGTTITSKGGANA VVIGEGEKDHAPMLYNGEEVGNGDGP IVIGEGEIDEAPMLYIGEKVGTGRGD-.....-AVDIAVDPIEGTRMTAMGQANA VVIGEGEKDEAPMLYNGEEVGTGFGP $\ldots$ IVIGEGERDDAPMLYIGEEVGICTREDAKSFCNPDELVEIDIAVDPCEGTNLVAYGQNGS IVIGEGERDEAPMLYIGEEVGICTRPDAAOYCNPEELIEIDIAVDPCEGTNLCAYGQPGS VVIGEGERDEAPMLYIGEEVGAG-GP-......-NTDIALDPLEGTTITAKGSANA $\cdot * * * * * * * * * * * * * * * * *$

$*: * * *: * *:: *$.

LTVLAMADKGGFLNAPD-VYMOKIAVGGINAPKGIVDLDDSVTNNLKRIAEFKGVHMSAL ISVLAVADRGTMFDPSAVFYMNKIAVGP - -DAAHVLDITAPISENIRAVAKVKDLSVRDM LAVLAVGDKGCFLNAPD-MYMEKLIVGP--GAKGTIDLNLPLADNLRNVAAALGKPLSEL ISILAAAERGTMYDPSSVFYMKKIAVGP - -EAAGKIDIEAPVAHNINAVAKSKGINPSDV MAVLAISEKGGLFAAPD-FYMKKLAAPP--AAKGHVDIDKSATENLKILSDCLNRSIEEL MAVLAISEKGGLFAAPD-FYMKKLAAPP - -AAKGKVDIRNSATENLKILSECLDRAIDEL LAVIAMAEHGGFLNAPD-VYMNKIAVGG-NYPEGIVDLDAEPRDNLNALAKAKGVEVEDL

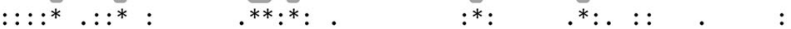

VVCTMDRPRHEHIIKEARECGARVILINDGDVSGVIATATENSGIDVYIGTGGAPEGVLA TVCILDRPRHAQLIHDVRATGARIRLITDGDVAGAISACRPHSGTDLLAGIGGTPEGIIA TVTILAKPRHDAVIAEMQQ LGVRVFAIPDGDVAASILTCMPDSEVDVLYGIGGAPEGVVS TVVVLDRPRHIELIADIRRAGAKVRLISDGDVAGAVAAAQDSNSVDIMMGTGGTPEGIIT VVVVMDRPRHKELIQEIRNAGARVRLISDGDVSAAISCAFSGTNIHALMGIGAAPEGVIS VVVMKRDRHNDLIQEIRDAGARVQLISDGDVSAALACAFSGTNIHALMGIGAAPEGVIS VVCILDRPRHQEIIAKVREAGARIMLINDGDVSGVIATTNYNAGVDMYMGVGGAPEGVLA .* : : ** :*.: *.:: *****:. : . **.:***:::

AAALKCLGGQMQARLIFNDEEEI - - - - - - KRAHRLGITDLNKKYDIDDLA-SG AAAIRCMGGAIOAOLAPRDDAER - . - . - . - RKALEAGYD-LNOVLTTEDLVSGE AAVIRALDGDMNGRLLARHDVKGDNEENRRIGEQELARCKAMGIE-AGKVLRLGDMARSD ACAMKCMGGEIQGILAPMNDFER - - . - . - QKAHDAGLV-LDQVLHTNDLVSSD AAAMRCLGGHFQGQLIYDPEVVKTG-LIGESREGNLERLASMGIKNPDQVYNCEELACGE AAAMRALGGHFQGQLVYDPAVVMTKEWANRTREGNLEELKKAGITDPDKVYEAEELASGE AAALRCIGGQMQGRLVFRNDDER - - - . - - ARAQRWGITDFDRKYALHDLA-GG

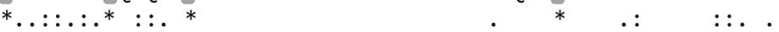

DIVFAATGVTDGNMLQGVKRVNSTRRGSYAVTHSVVMRSTTKTVRHITAEHSFDFKEGIE NVFFCATGVTDGDLLKGVRYYP- - - - -GGCTTHSIVMRSKSGTVRMIEAYHRLSKLNEYS NVIFSATGITKGDLLEGISRKG - - - - NIATTETLLIRGKSRTIRRIQSIHYLDRKDPEM NCYFVATGVTNGDMLRGVSYRA- - - - NGATTRSLVMRAKSGTIRHIESVHQLSKLQEYS 327 TVLFAACGITPGTLMEGVRFFH - - - - -GGVRTQSLVISSQSSTARFVDTVHMKESPK-VI 342 TVLFAACGITPGMLMKGVRFFK - - - - -GGARTQSLVISTQSKTARFVDTIHMFDQQLKSL $\quad 344$ DVMFAATGVTDGTMLQGVRRRY - - - - -KGAQTHSMVMRSSTGTVRLITADHNFQRKTWTG 323

$$
\text { ***:**::.*: } \quad \text { *.: : : : :**: : * . }
$$

Fig. 2 Sequence comparison of FtglpX gene with other class II FBPases. CLUSTALW alignment of $F$. tularensis FBPaseII with M. tuberculosis (Rv1099c), Escherichia coli (PDB 3D1R), Corynebacterium glutamicum (Accession WP 003856830.1), Synechocystis sp. PCC6803 (Accession WP 010872613), Thermosynechococcus elongatus ('̄ual FBPase/SBPase) (PDB 5A5L), and Rhodovibrio salinarium (Accession WP_027288916.1) identified 73 conserved residues. The sequence identity ranged from 40.2 to $64.2 \%$ against $F$. tularensis. Invariant positions are indicated by asterisks (*) under the alignment, while highly conserved and weakly conserved positions are indicated by colons and periods, respectively 


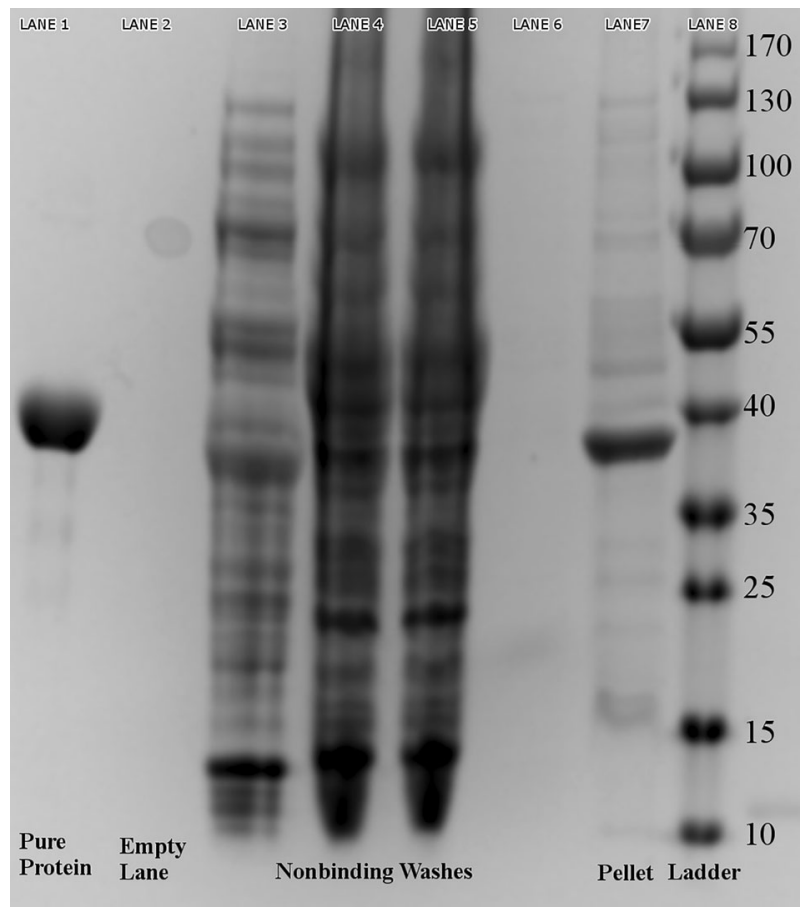

Fig. 3 Purification of FtFBPaseII. Purification of FtFBPaseII was carried out with his-tag nickel affinity purification procedures, which resulted in highly pure protein of approximately $37 \mathrm{kDa}$, as seen in Lane 1 . Lane 8 contains PageRuler Prestained Protein Ladder of indicated size bands in kDa. Lanes 3-6 contain non-binding washes. Lane 7 is the urea-soluble portion of the pellet

linear for enzyme concentration up to $50 \mathrm{nM}$. FtFBPaseII was inhibited by $\mathrm{Li}^{+}$with an $\mathrm{IC}_{50}$ value of $100 \mathrm{mM}$ in the coupled assay. Adenosine diphosphate had $28 \%$ inhibitory activity of FtFBPaseII at $1 \mathrm{mM}$ and precipitated at higher concentrations. High concentrations of phosphate also precipitated in the enzyme solution; nevertheless, $69 \%$ inhibition of the enzyme was detected at $150 \mu \mathrm{M}$.

\section{Discussion}

Recent experiments have suggested the essentiality of the $g l p X$ gene in F. tularensis [3]. These studies followed the growth of $F$. novicida, a subspecies of $F$. tularensis, in glucose and glycerol. While these studies demonstrate that the $g l p X$-encoded protein is required for growth on gluconeogenic substrates, they do not functionally verify the enzymatic activity of the encoded protein.

Our experimental plan to verify the functional activity was based on complementation of known E. coli mutants lacking significant FBPase activity by the FtglpX-encoded protein. While the complementation with E. coli strains JLD2402 and JLD2404 does not rule out nonspecific complementation, it does indicate that the FtglpX-encoded protein helps such strains grow on gluconeogenic substrates.

Complementation studies show that the $\mathrm{pET} 15 \mathrm{~b}-\mathrm{glp} X$ plasmid was able to restore growth of the E. coli strains (lacking a functional FBPase I) on glycerol and independently verify that the 

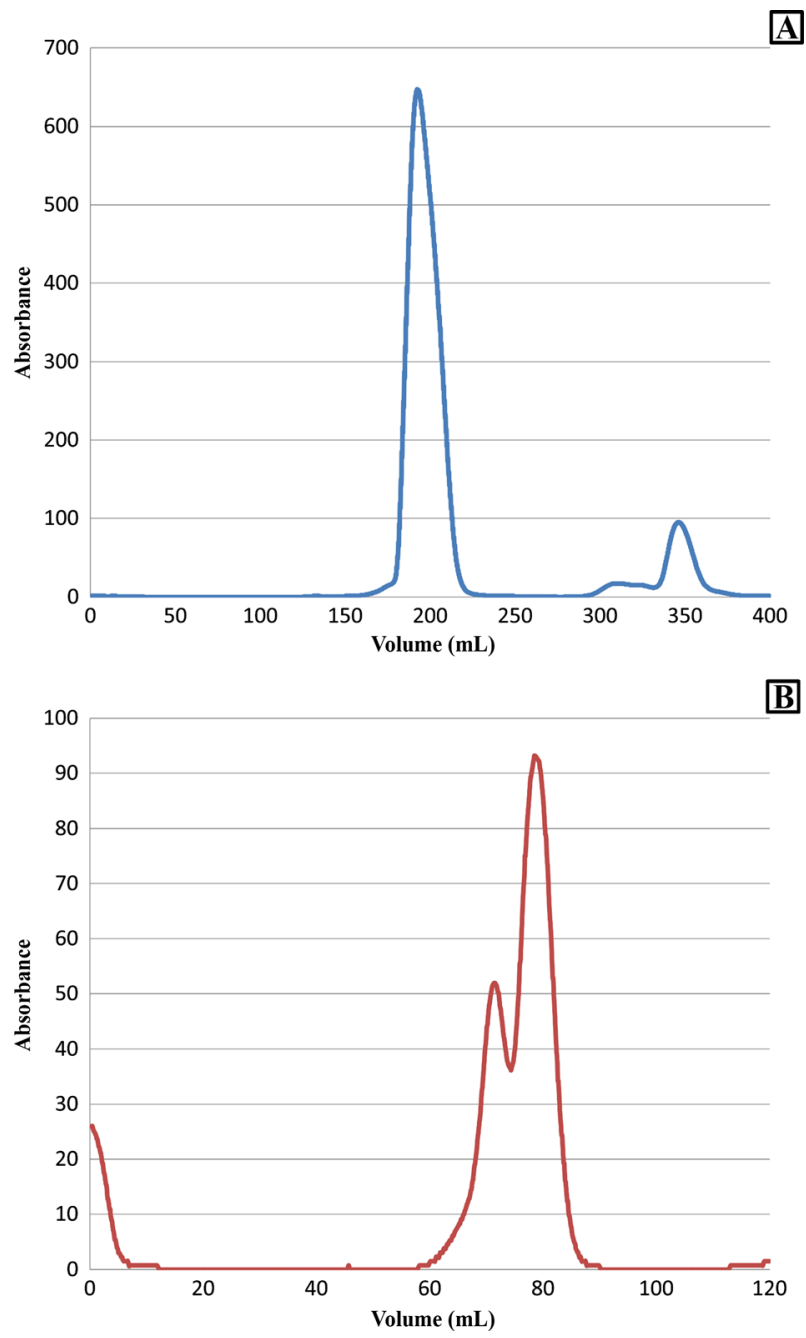

Fig. 4 SEC chromatogram for FtFBPaseII. A main peak at about $190 \mathrm{~mL}$ corresponds to the $F t$ FBPaseII tetramer (a). A small peak at $350 \mathrm{~mL}$ might be the diluted monomeric form of FBPase protein or other buffer ingredients. The peak maximum of first peak was about $650 \mathrm{mAu}$. SEC was repeated for $F t$ FBPaseII protein for molecular weight estimation (b). The chromatogram indicated the presence of dimeric and tetrameric species (63.8 and $124.9 \mathrm{kDa}$, respectively) by calculation from a calibration curve using molecular weight standards, thyroglobulin (bovine) $670 \mathrm{kDa}$, gamma globulin (bovine) $158 \mathrm{kDa}$, ovalbumin (chicken) $44 \mathrm{kDa}$, myoglobulin (horse) $17 \mathrm{kDa}$, and vitamin B12 $1350 \mathrm{Da}$. Calibration curve can be found in previous publication [6]. Peak maximums are about 52 and $93 \mathrm{mAu}$

$g l p X$-encoded FBPase of $F$. tularensis is a functional FBPase. Since the $E$. coli control strains do not have FBPase enzymes, it can be interpreted that FBPase activity is needed for growth on glycerol. This work independently verifies that the $g l p X$-gene encoded protein in F. tularensis is indeed an FBPase which can successfully complement a $\Delta f b p E$. coli strain (JB 108). Furthermore, the IPTG-induced overexpression of FBPase II from $F$. tularensis in a $\triangle f b p$ E. coli strain (JB 108) by pET15b-FtglpX proves that overexpression of this protein allows growth and proliferation of the $E$. coli strain. 


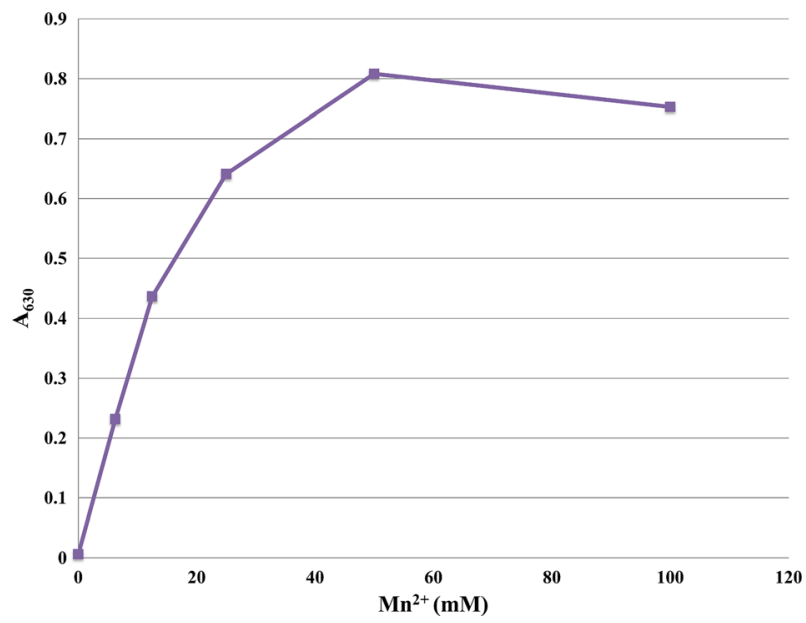

Fig. $5 \mathrm{FtFBPaseII}$ activity is dependent on $\mathrm{Mn}^{2+}$. The activity of $\mathrm{FtFPBaseII}$ was measured with a malachite green assay using $630 \mathrm{~nm}$ as detection wavelength. No activity was detected without $\mathrm{Mn}^{2+}$ and maximum activity was achieved at $50 \mathrm{mM} \mathrm{Mn}{ }^{2+}$

Additionally, the primary sequence comparison of $F t$ FBPaseII with other known Class II FBPases also indicates that several regions are conserved and important catalytic residues in

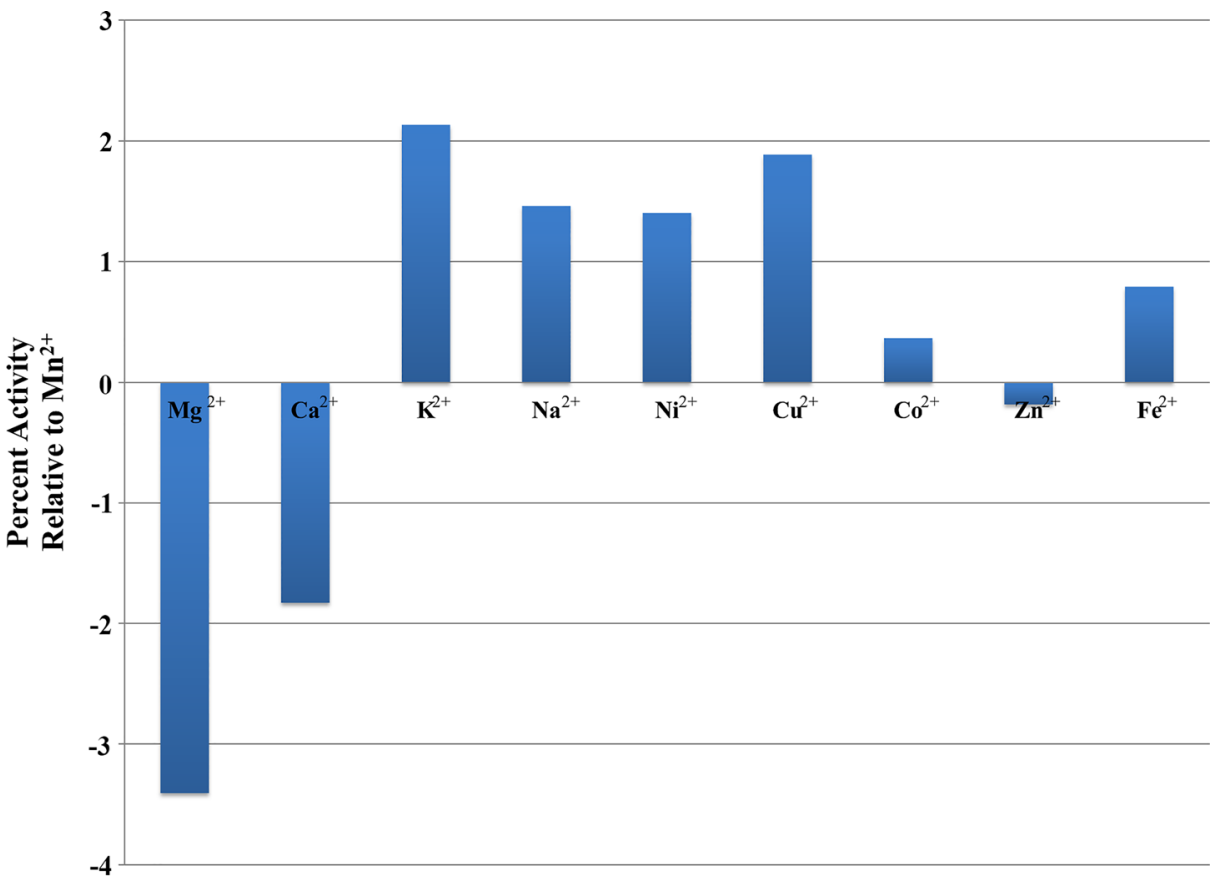

\section{Metal Ion}

Fig. 6 Metal requirement for FtFBPaseII activity. Malachite green assay was conducted to find a metal ion that would allow for activity of $F t$ FBPaseII. Only the presence of $\mathrm{Mn}^{2+}$ in the assay allowed for sufficient production of inorganic phosphate to be detected 


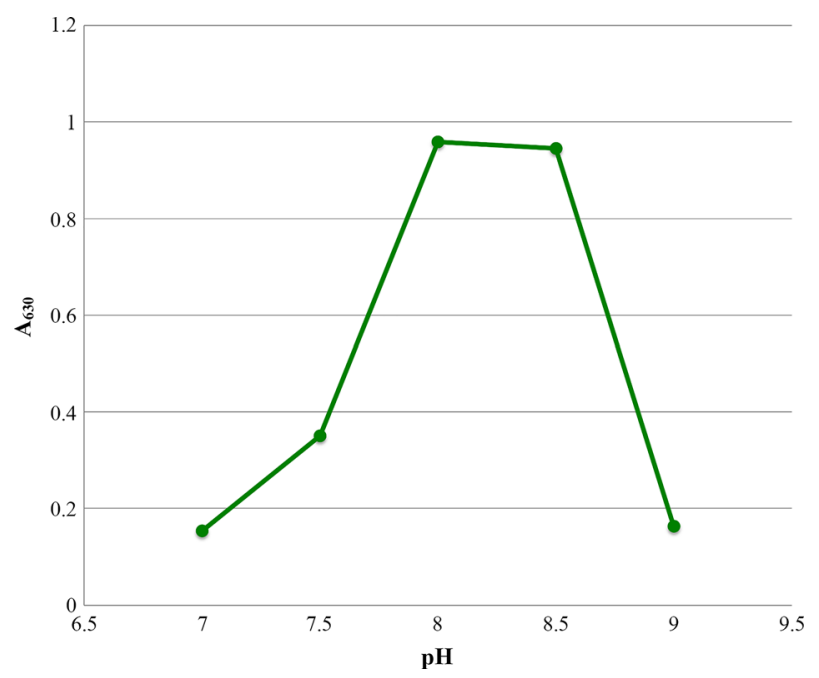

Fig. $7 \mathrm{Ft}$ FBPaseII activity is dependent on $\mathrm{pH}$. Using a malachite green assay with $630 \mathrm{~nm}$ detection wavelength, the activity of FtFPBaseII was optimal between 8.0 and $8.5 \mathrm{pH}$ units in $50 \mathrm{mM}$ tRIS buffer

the enzyme are conserved. This work together with the complementation studies verifies that the encoded protein is an FBPaseII.

FBPase enzymes have been the subject of many drug discovery programs and other fields of research culminating with over 162 structures available in the protein data bank. A few of

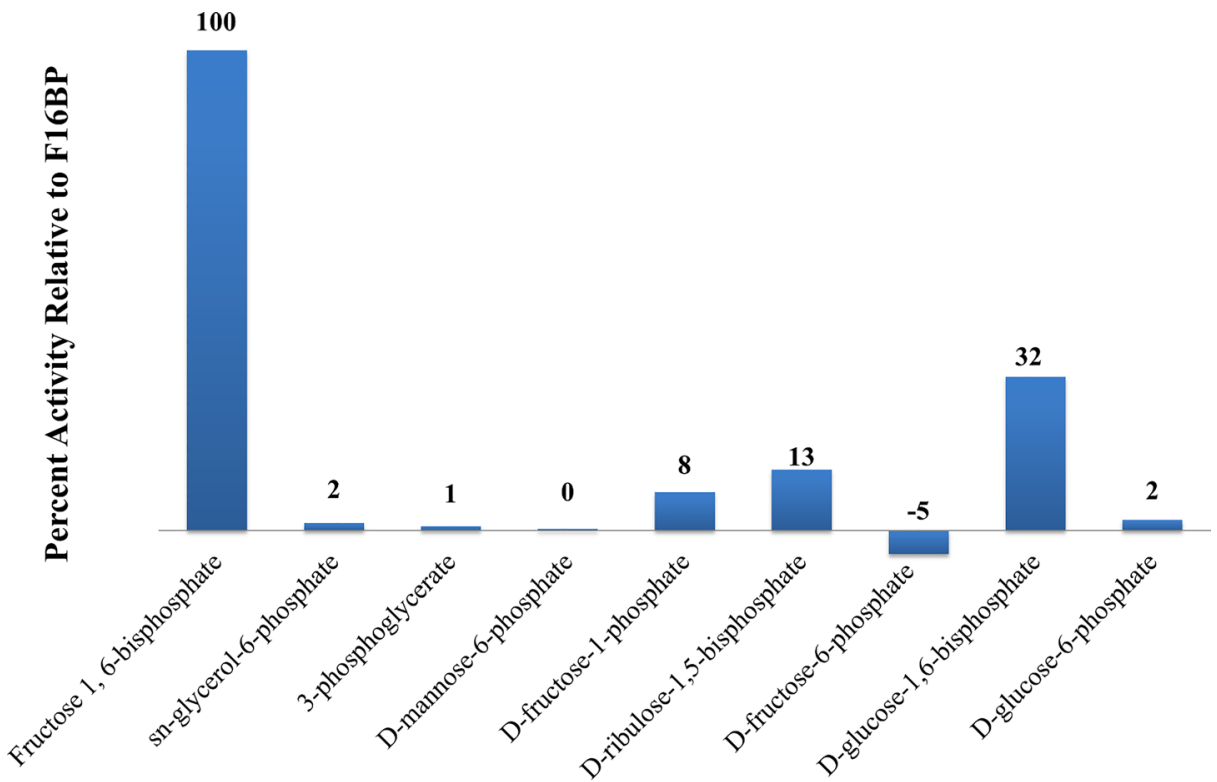

Substrate

Fig. 8 Substrate specificity for FtFBPaseII activity. Malachite green assay was performed to quantify the production of inorganic phosphate from various substrates. F16BP had the greatest activity and is presumed to be the natural substrate. D-glucose-1,6-bisphosphate, D-ribulose-1,5-bisphosphae, and D-fructose-1-phosphate have limited phosphate liberation by FtFBPaseII 


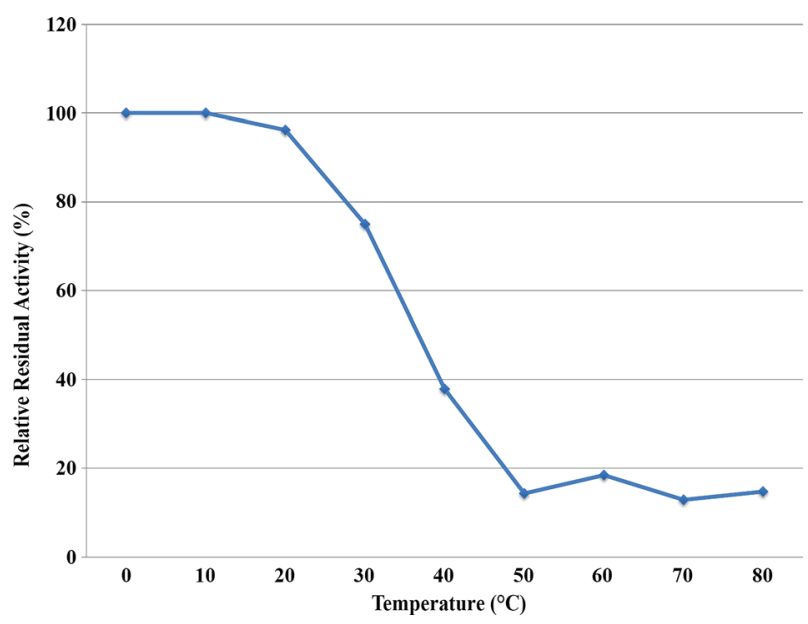

Fig. 9 Relative residual activity of FtFBPaseII after heating. Using a coupled assay, the activity of $F t$ FPBaseII was measured after $30 \mathrm{~min}$ at indicated temperatures. Activity is plotted relative to a sample incubated on ice. The protein remained stable when incubated below room temperature. At $30-40{ }^{\circ} \mathrm{C}$, there was a marked decline in activity, and at $50{ }^{\circ} \mathrm{C}$ and above, activity of the enzyme was negligible

these enzymes have been subjected to extensive biochemical characterization, most notably, those from E. coli [14, 19], Corynebacterium glutamicum [15], and M. tuberculosis [6].

The $E$. coli FBPase is a dimer [14, 19] in solution while those from C. glutamicum [15] and M. tuberculosis [6] are both tetramers. Interestingly, we found that the quaternary structure was dependent on the protein concentration. While it is possible that there were two different molecular weight structures found at lower protein concentration, it is also possible that the protein had adopted two different conformations [20,21]. In either case, we can conclude that the protein is more stable at the higher concentration.

$F t$ FBPasell is dependent on $\mathrm{Mn}^{2+}$ for activity, as is the E. coli enzyme [14] while those from C. glutamicum and M. tuberculosis can use either $\mathrm{Mn}^{2+}$ or $\mathrm{Mg}^{2+}$ [15]. FBPase from M. jannaschii could substitute $\mathrm{Zn}^{2+}$ [13]. F. tularenesis was found to have weak sensitivity to $\mathrm{Li}^{+}$, similar to $E$. coli with an $\mathrm{IC}_{50}$ of $70 \mathrm{mM}$ [19]. $\mathrm{Li}^{+}$sensitivity in other organisms was more pronounced with $\mathrm{IC}_{50}$ values of $200 \mu \mathrm{M}$ (M. tuberculosis) [6] and $140 \mu \mathrm{M}$ (C. glutamicum) [15].

Substrate affinity and specificity between differing species' enzymes may give us critical insight into active site differences. The $\mathrm{K}_{\mathrm{m}}$ for $F$. tularensis is comparable to $C$. glutamicum with a $\mathrm{K}_{\mathrm{m}}$ of $14 \mu \mathrm{M}$ [15], while E. coli and M. tuberculosis $\mathrm{K}_{\mathrm{m}}$ values are higher at $35 \mu \mathrm{M}$ [14] and $44 \mu \mathrm{M}$ [6], respectively. $\mathrm{V}_{\max }$ of $C$. glutamicum of 5.4 units/mg [15] was highest, with E. coli Class II at 3.3 units/mg [13] and M. tuberculosis at 1.6 units/mg [6]. $\mathrm{k}_{\text {cat }}$ values of 1.0 [6] M. tuberculosis and 3.2 [15] C. glutamicum and 14.6 [22] E. coli Class I s ${ }^{-1}$. While $\mathrm{k}_{\mathrm{cat}}{ }$ $\mathrm{K}_{\mathrm{m}}$ values had a larger range of 22.7 [6] (M. tuberculosis), 57 [14] (E. coli Class II), 948 [22] (E. coli Class I), and $236 \mathrm{mM}^{-1} \mathrm{~s}^{-1}$ [15] (C. glutamicum). E. coli had low activity with substrates fructose L-phosphate and ribulose 1,5-bisphosphate [14] and glucose 1,6bisphosphate [19]. C. glutamicum has low activity with glucose-6-phosphate [15].

FBPases are known to require bivalent metal ions and have sensitivity to lithium. These differences in absolute metal requirement, substrate affinity, substrate specificity, and lithium sensitivity may be the key indicators for targeting a particular enzyme for structure-based drug design [23]. The subtle active site changes from one species to another elucidated by structural 
analysis will give us critical insight. Substrate specificity differences give important enzymatic activity information for rational drug design [24]. With the aid of computational energy minimization, examination of the binding differences of the tested substrates could be used as a starting point.

It is assumed that inhibition of the enzyme by phosphate is due to binding of phosphate in the active site where the substrate's own phosphate groups would bind. However, inhibition by adenosine diphosphate (ADP) brings up questions of the presence of an allosteric site. AMP is an allosteric inhibitor of human FBPase [25]. Future work to find the X-ray structure and further biochemical characterization with $F t$ FBPase and ADP should tell us the mechanism of inhibition.

The genetic complementation results prove that the $F$. tularensis $g l p X$ gene encodes for a protein that possesses FBPase activity and can complement the E. coli $\Delta f b p$ strain. Bioinformatics results indicate that it is a Class II FBPase. FtFBPaseII was easily purified following standardized protocols. Biochemical characterization has provided valuable and novel information for drug discovery and should be pursued as an ongoing research activity.

The major bottlenecks in the process of structure-based drug discovery against this target are the availability of a purified protein target and the ability to crystallize the target in a robust crystal form. We have succeeded in the purification and biochemical characterization of the enzyme. The biochemical and structural understanding of this validated enzyme target can serve as a starting point for a structure-based drug discovery approach for this highly virulent bacterium.

Acknowledgements We would like to acknowledge Professor Michael E. Johnson at the University of Illinois at Chicago for the use of the FPLC instrument and Professor Chuan He at the University of Chicago for providing help with the SEC.

Open Access This article is distributed under the terms of the Creative Commons Attribution 4.0 International License (http://creativecommons.org/licenses/by/4.0/), which permits unrestricted use, distribution, and reproduction in any medium, provided you give appropriate credit to the original author(s) and the source, provide a link to the Creative Commons license, and indicate if changes were made.

\section{References}

1. Dennis, D. T., Inglesby, T. V., Henderson, D. A., Bartlett, J. G., Ascher, M. S., Eitzen, E., et al. (2001). Tularemia as a biological weapon: medical and public health management. Journal of the American Medical Association, 285(21), 2763-2773.

2. Kadzhaev, K., Zingmark, C., Golovliov, I., Bolanowski, M., Shen, H., Conlan, W., et al. (2009). Identification of genes contributing to the virulence of Francisella tularensis SCHU S4 in a mouse intradermal infection model. PloS One, 4(5), e5463. doi:10.1371/journal. pone.0005463.

3. Brissac, T., Ziveri, J., Ramond, E., Tros, F., Kock, S., Dupuis, M., et al. (2015). Gluconeogenesis, an essential metabolic pathway for pathogenic Francisella. Molecular Microbiology, 98(3), 518-534. doi:10.1111/mmi.13139.

4. Gutka, H. J., Wang, Y., Franzblau, S. G., \& Movahedzadeh, F. (2015). Glpx gene in Mycobacterium tuberculosis is required for in vitro gluconeogenic growth and in vivo survival. PloS One, 10(9), e0138436. doi:10.1371/journal.pone.0138436.

5. Movahedzadeh, F., Rison, S. C., Wheeler, P. R., Kendall, S. L., Larson, T. J., \& Stoker, N. G. (2004). The Mycobacterium tuberculosis Rv1099c gene encodes a GlpX-like class II fructose 1,6-bisphosphatase. Microbiology, 150(Pt 10), 3499-3505. doi:10.1099/mic.0.27204-0.

6. Gutka, H. J., Rukseree, K., Wheeler, P. R., Franzblau, S. G., \& Movahedzadeh, F. (2011). glpX gene of Mycobacterium tuberculosis: heterologous expression, purification, and enzymatic characterization of the encoded fructose 1,6-bisphosphatase II. Applied Biochemistry and Biotechnology, 164(8), 1376-1389. doi:10.1007/s12010-011-9219-x. 
7. Gutka, H. J., Franzblau, S. G., Movahedzadeh, F., \& Abad-Zapatero, C. (2011). Crystallization and preliminary X-ray characterization of the glpX-encoded class II fructose-1,6-bisphosphatase from Mycobacterium tuberculosis. Acta Crystallographica. Section F, Structural Biology and Crystallization Communications, 67(Pt 6), 710-713. doi:10.1107/S1744309111014722.

8. Hines, J. K., Fromm, H. J., \& Honzatko, R. B. (2006). Novel allosteric activation site in Escherichia coli fructose-1,6-bisphosphatase. The Journal of Biological Chemistry, 281(27), 18386-18393. doi:10.1074/jbc. M602553200.

9. Hines, J. K., Chen, X., Nix, J. C., Fromm, H. J., \& Honzatko, R. B. (2007). Structures of mammalian and bacterial fructose-1,6-bisphosphatase reveal the basis for synergism in AMP/fructose 2,6-bisphosphate inhibition. The Journal of Biological Chemistry, 282(49), 36121-36131. doi:10.1074/jbc.M707302200.

10. Nishimasu, H., Fushinobu, S., Shoun, H., \& Wakagi, T. (2004). The first crystal structure of the novel class of fructose-1,6-bisphosphatase present in thermophilic archaea. Structure, 12(6), 949-959. doi:10.1016/j. str.2004.03.026.

11. Jules, M., Le Chat, L., Aymerich, S., \& Le Coq, D. (2009). The Bacillus subtilis ywjI (glpX) gene encodes a class II fructose-1,6-bisphosphatase, functionally equivalent to the class III Fbp enzyme. Journal of Bacteriology, 191(9), 3168-3171. doi:10.1128/JB.01783-08.

12. Stec, B., Yang, H., Johnson, K. A., Chen, L., \& Roberts, M. F. (2000). MJ0109 is an enzyme that is both an inositol monophosphatase and the 'missing' archaeal fructose-1,6-bisphosphatase. Nature Structural Biology, 7(11), 1046-1050. doi:10.1038/80968.

13. Rashid, N., Imanaka, H., Kanai, T., Fukui, T., Atomi, H., \& Imanaka, T. (2002). A novel candidate for the true fructose-1,6-bisphosphatase in archaea. The Journal of Biological Chemistry, 277(34), 30649-30655. doi:10.1074/jbc.M202868200.

14. Donahue, J. L., Bownas, J. L., Niehaus, W. G., \& Larson, T. J. (2000). Purification and characterization of glpX-encoded fructose 1, 6-bisphosphatase, a new enzyme of the glycerol 3-phosphate regulon of Escherichia coli. Journal of Bacteriology, 182(19), 5624-5627.

15. Rittmann, D., Schaffer, S., Wendisch, V. F., \& Sahm, H. (2003). Fructose-1,6-bisphosphatase from Corynebacterium glutamicum: expression and deletion of the fbp gene and biochemical characterization of the enzyme. Archives of Microbiology, 180(4), 285-292. doi:10.1007/s00203-003-0588-6.

16. Baykov, A. A., Evtushenko, O. A., \& Avaeva, S. M. (1988). A malachite green procedure for orthophosphate determination and its use in alkaline phosphatase-based enzyme immunoassay. Analytical Biochemistry, 171(2), 266-270.

17. Studier, F. W., \& Moffatt, B. A. (1986). Use of bacteriophage T7 RNA polymerase to direct selective highlevel expression of cloned genes. Journal of Molecular Biology, 189(1), 113-130.

18. Xiao, Q., Zhang, F., Nacev, B. A., Liu, J. O., \& Pei, D. (2010). Protein N-terminal processing: substrate specificity of Escherichia coli and human methionine aminopeptidases. Biochemistry, 49(26), 5588-5599. doi:10.1021/bi1005464.

19. Brown, G., Singer, A., Lunin, V. V., Proudfoot, M., Skarina, T., Flick, R., et al. (2009). Structural and biochemical characterization of the type II fructose-1,6-bisphosphatase GlpX from Escherichia coli. The Journal of Biological Chemistry, 284(6), 3784-3792. doi:10.1074/jbc.M808186200.

20. Ali, M. H., \& Imperiali, B. (2005). Protein oligomerization: how and why. Bioorganic \& Medicinal Chemistry, 13(17), 5013-5020. doi:10.1016/j.bmc.2005.05.037.

21. Hashimoto, K., Nishi, H., Bryant, S., \& Panchenko, A. R. (2011). Caught in self-interaction: evolutionary and functional mechanisms of protein homooligomerization. Physical Biology, 8(3), 035007. doi:10.1088 /1478-3975/8/3/035007.

22. Kelley-Loughnane, N., Biolsi, S. A., Gibson, K. M., Lu, G., Hehir, M. J., Phelan, P., et al. (2002). Purification, kinetic studies, and homology model of Escherichia coli fructose-1,6-bisphosphatase. Biochimica et Biophysica Acta, 1594(1), 6-16.

23. Bruijnincx, P. C., \& Sadler, P. J. (2008). New trends for metal complexes with anticancer activity. Current Opinion in Chemical Biology, 12(2), 197-206. doi:10.1016/j.cbpa.2007.11.013.

24. Liu, C., Dunaway-Mariano, D., \& Mariano, P. S. (2017). Rational design of reversible inhibitors for trehalose 6-phosphate phosphatases. European Journal of Medicinal Chemistry, 128, 274-286. doi:10.1016/j.ejmech.2017.02.001.

25. Gidh-Jain, M., Zhang, Y., van Poelje, P. D., Liang, J. Y., Huang, S., Kim, J., et al. (1994). The allosteric site of human liver fructose-1,6-bisphosphatase. Analysis of six AMP site mutants based on the crystal structure. The Journal of Biological Chemistry, 269(44), 27732-27738. 